\title{
Probability-Statistical Models to Forecast Hydraulic Fracturing Efficiency
}

\author{
Klara Fatkullinovna Gabdrakhmanova ${ }^{1, *}$, Gulnara Rishadovna Izmaylova ${ }^{2}$, Eldar Faritovich Samigullin ${ }^{3}$, and Rishat \\ Sabirovich Gilmanov ${ }^{4}$
}

${ }^{1}$ Department of Information Technologies, Mathematics and Natural Sciences Ufa State Petroleum Technological University, Branch of the University in the City of Oktyabrsky, Oktyabrsky, the Republic of Bashkortostan, Russia

${ }^{2}$ Department of Oil and Gas Field Exploration and Development Ufa State Petroleum Technological University, Branch of the University in the City of Oktyabrsky, Oktyabrsky, the Republic of Bashkortostan, Russia

${ }^{3}$ Kazan National Research Technological University, Faculty of Control and Automation, Gr. 8101-21, Kazan, the Republic of Tatarstan, Russia

${ }^{4}$ Department of Oil and Gas Field Exploration and Development, Gr. MGR12-19-11, Ufa State Petroleum Technological University, Branch of the University in the City of Oktyabrsky, Oktyabrsky, the Republic of Bashkortostan, Russia

\begin{abstract}
The article discusses the criteria for choosing fracture parameters by length, height and amount of proppant to be injected. The criteria, chosen on the basis of for probabilistic and statistical analysis are to ensure adequate application of multi- and single-stage hydraulic fracturing technique. The statistical indicators analysis of the multistage hydraulic fracturing application on the AS12-3 horizon made it possible to clarify the ranges of main hydraulic fractures parameters in terms of their length, volume, number of fractures and the weight of the injected proppant.
\end{abstract}

\section{Introduction}

Both in Russia and abroad hydraulic fracturing technologies are widely used to improve production efficiency and to increase oil flow. The technology is based on the mechanism of cracks formation and propagation in rocks. And a little amount of works describing the optimal number of hydraulic fracturing stages and estimating the distances between the created fractures has been published. Therefore, it called forth the need to develop the new criteria for multiple hydraulic fracturing employment in integrated reservoir stimulation technologies in field conditions. The probabilistic-statistical approach was used as the basis for the criteria development.

The study of hydraulic fracturing efficiency especially in conditions of hard-to-recover oil reserves, is the subject study of many foreign and Russian scientists. In their works many scientists [1-4] are considering ways to improve the multi-stage hydraulic fracturing techniques employed in an anisotropic heterogeneous oil-saturated reservoir.

The authors of the study [5] describe the possibility of assessing the productivity index by indirect data at the stage of the first design documents and when modeling oil recovery processes using the experience of developing the fields that have been in operation for a long period.

Of interest are the studies carried out by the authors of the research [6] who investigate necessary the amount of the proppant to be injected. They introduce new governing equations that allow to describe the fracture closure process and analyze the influence of fluid viscosity, its density, size and permeability of the formation. These studies will be useful when choosing a proppant composition.

Despite numerous studies in the field of reservoir productivity increasing with single- and multi-stage hydraulic fracturing techniques employing, some unsolved questions remain. The authors studied the publications and textbooks $[11,12]$, carried out research using the apparatus of mathematical statistics in conditions of the Shirotnoye Priobje Latitudinal $\mathrm{Ob}$ Region) oil field and identified the goal and objectives of the study.

The purpose of the study is to determine the efficiency criteria for hydraulic fracturing using a probabilistic-statistical approach.

To achieve this goal we are to fulfill the following tasks:

1. Statistical analysis of existing hydraulic fracturing techniques in Russia and abroad;

2. Theoretical studies of the single- and multi-stage hydraulic fracturing operations efficiency;

3. Determination of the hydraulic fracturing technology efficiency criteria.

* Corresponding author: klara47@ mail.ru 


\section{Research results. Geological field studies of the $\mathrm{Ob}$ river region field}

The paper presents a brief geological and physical characteristic of the AS12-3 horizon reservoir properties. The conditions of the horizon contribute to the formation of hard-to-recover reserves in it. A probabilisticstatistical analysis of the hydraulic fracturing is performed in it. The substantiation for the production stimulation method choosing which is based on the onestage hydraulic fracturing technology application is given.

After the field efficiency statistical data processing, quantitative criteria for the selection of fracture parameters by its length, height and the amount of proppant injected into it have been established. On the basis of their implementation, it became possible to raise the field efficiency of one-stage hydraulic fracturing and ensure an increase in annual cumulative production by at least $10-15 \%$. However, after some time (4 years), the field efficiency of one-stage hydraulic fracturing began to decline, and this fact required finding ways to improve it by introducing its multi-stage modification. The analysis of the field-testing results made it possible to obtain quantitative criteria for the multistage hydraulic fracturing optimization on the basis of a reasonable choice of both the length and volume of fractures, and their number. The analysis made it possible to achieve the planned oil recovery factor during the AS12-3 horizon development within the terms established and agreed with the State Reserves Committee of the Russian Federation.

Figure 1 shows the histograms of the distribution of the effective oil-saturated capacity of the AS12-3 formation. From the histogram it can be seen that the effective oil-saturated capacity is no more than $50 \%$ of the actual thickness of this formation and its prevailing value from 3 to 7 meters is $60 \%$, and the remaining thicknesses from 1 to $3 \mathrm{~m}$ and from 8 to $10 \mathrm{~m}$ accounts for less than $40 \%$.

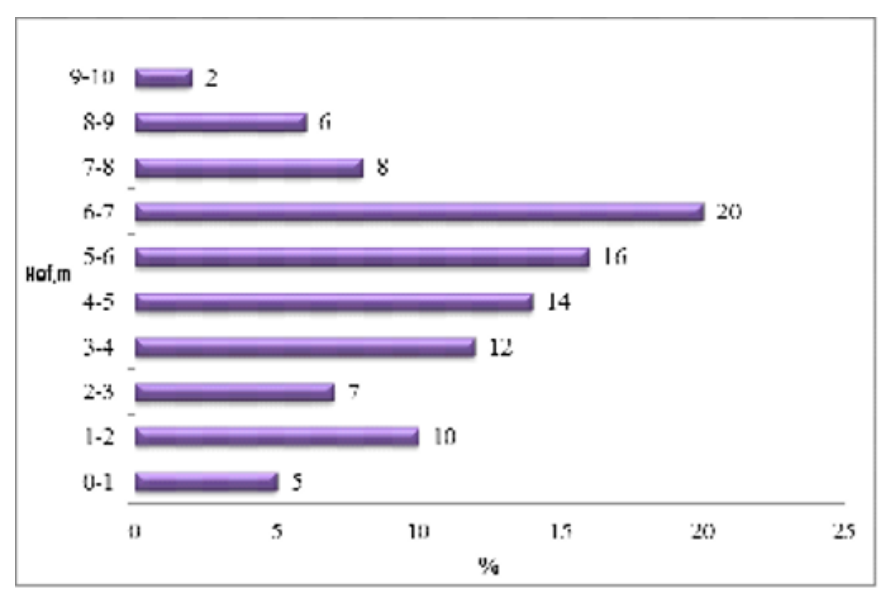

Fig. 1. Histogram of the effective oil-saturated capacity of the AS12-3 reservoir distribution.

The productive formation has a fairly low net-togross ratio. Its proportion up to 0.4 is about $90 \%$ (Fig. 3 ), which is due to the relatively high clay ratio $(\mathrm{Kgl}=5$
$8 \%$ ), despite rather high average intergranular porosity of the formation (Fig. 4 ) equal to $19 \%$. This is the reason for its low permeability $(45-90 \mathrm{mpc})$ with an average oil saturation of 62 to $76 \%$.

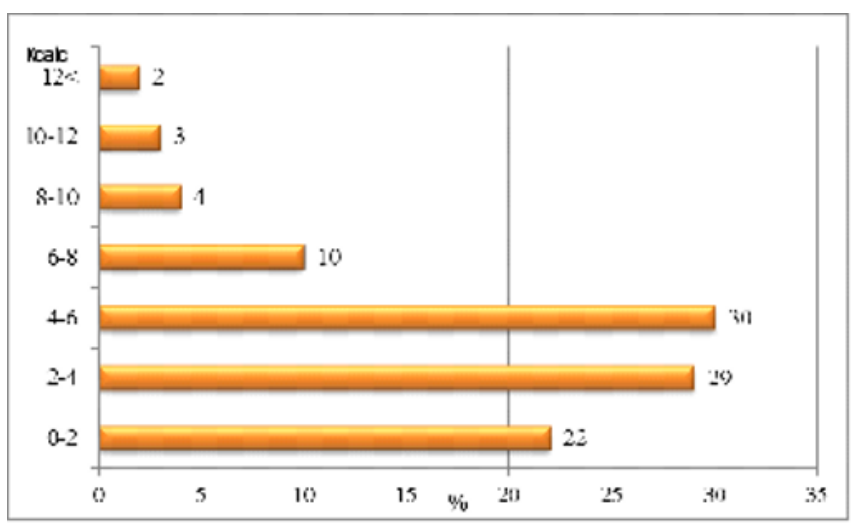

Fig. 2. Histogram of net-to-gross distribution, productive formation AS12-3.

Ultimately, the given reservoir properties of the AS12-3 formation make it possible to classify the oil reserves in it as hard-to-recover. This results in their uneven development over the bedding area.

The deterioration of the reserves structure in the process of the AS12-3 formation intensive development led, despite the increase in the operating well stock by 2001 to 80 units, to the beginning of a rapid decline in the current annual production and became the main reason for the search for more efficient EOR technique. By the beginning of 2010, after various intensification techniques application (hydrochloric acid treatment, thermal implosion, horizontal well and horizontal sidetrack) and a thorough analysis of the obtained results, the choice alighted on the one-stage hydraulic fracturing technique [3].

In accordance with the design task, the hydraulic fracturing mode was selected with the aim of obtaining a single fracture in the productive strata with a height (Hcr) of up to $0.8-0.9 \mathrm{Hl}$, a length of Lcr up to 70-80 m and an opening (B) up to $3-5 \mathrm{~mm}$.

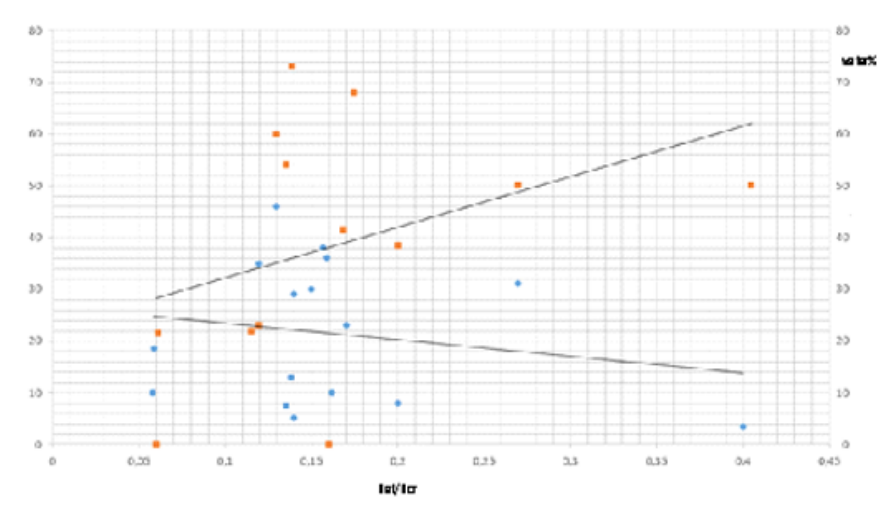

Fig. 3. Dependence of the well production rate on the length and height of the fracture after a single-interval hydraulic fracturing.

After analyzing the above dependences, it can be assumed that with an increase in the length of the 
fracture, the flow rate will increase according to the Darcy-Poisel law, and with an increase in height, on the contrary, a faster flooding occurs.

The evaluation of the hydraulic fracturing efficiency turned to be about $50 \%$. The analysis of the unsuccessful hydraulic fracturing showed that they, as a rule, are accompanied by low debit and an increase in water cut as compared to the initial one, although the selected wells were located in sufficiently high residual reserves zones.

The study of the structural features of the deposit and their comparison with the direction of the underlying basement faults showed that in the wing zones of the sedimentary strata areas the stressed rock patterns are formed, and they accompanied by the formation of natural fracturing, which has a predominantly axial (along the swell-like structure of the deposit) direction.

Comparison of unsuccessful hydraulic fracturing data with the location of wells in the zones of residual reserves concentration and the direction of natural fracturing in them showed that they were caused by the second wing of the fracture penetration into the zone of depleted reserves with a high level of water cut, which could explain their low efficiency [2]. Water breakthrough can also occur due to the the lower or upper aquifers opening by a crack. A decrease in water cut can occur due to an increase in the share of oil in the total flow rate, which came from previously closed, dead-end pores or stagnant zones.

In order to study the dependence of the technological efficiency of hydraulic fracturing on its implementation technique the influence of fracture parameters on it (the length, the height, the width, as well as the amount of proppant) was studied. The methodology was previously approved.

As a result, it was found that with an increase in the fracture length, the initial oil production rate increased and the water cut of the produced product decreased.

At the same time, it was found out that with an increase in the height of the fracture relative to the effective formation thickness, the oil production rate decreases, and the water cut, on the contrary, increases.

This behavior is obviously associated with a decrease in the effective oil-saturated reservoir thickness as reserves are depleted during long-term operation.

Further, it was found out that with an increase in the mass of the injected proppant, the oil production rate after hydraulic fracturing also increases. The obtained dependencies made it possible to significantly correct the technology of one-stage hydraulic fracturing in terms of increasing its not only technological, but the economic efficiency as well.

By applying the obtained criteria for choosing the optimal parameters of the single-stage hydraulic fracturing technology, it was possible not only to stop the outlined decline in the accumulated current production during the BV8-1 formation operation, but to ensure its increase as well.

\section{Efficiency of multistage hydraulic fracturing technique}

As an alternative to single-stage hydraulic fracturing, a multistage hydraulic fracturing technique has been developed. A horizontal wellbore is drilled into the formation and the technology of creating several fractures spaced at a certain interval from each other is used $[4,11]$.

The range of calculated and starting flow rates practically coincides, which indicates a fairly perfect method for predicting the field effect from multi-stage hydraulic fracturing [4]. However, after first 3 months, and then 6 months, real production rates begin to differ significantly from the calculated data. Moreover, this discrepancy occurs both in the direction of decreasing production rates, compared with the calculated data, and in the direction of their increase. This behavior is due to the manifestation of a systemic error in the calculations performed, since it is accompanied by a corresponding unaccounted-for increase in the water cut of the produced production in the first case and its decrease in the second.

Thus, as a result of the analysis performed, the relationship between the probability of a positive forecast for an increase in oil production and a decrease in its water cut, additional quantitative criteria were obtained that determine the optimal properties of the formed cracks, providing the necessary technological efficiency of the used EOR method, according to the forecast calculations.

\section{Results}

1. The productive horizon AS12-3 has a complex geological and physical structure and low filtration and storage properties, which significantly complicates its development and contributes to the active formation of hard-to-recover reserves in it;

2. Application of the technology for the BV8-1 horizon development intensification based on one-stage hydraulic fracturing has shown its effectiveness within a fairly limited time, not exceeding 3-4 years;

3. The use of multistage hydraulic fracturing technique on the AS12-3 horizon showed its higher efficiency compared to the single-stage hydraulic fracturing technique. However, the confirmation of positive predictive indicators from its application did not exceed $50 \%$;

4. The analysis of the statistical indicators of the field results of the multistage hydraulic fracturing application on the AS12-3 horizon made it possible to clarify the ranges of main hydraulic fractures parameters choice in terms of their length, volume, number of fractures and the weight of the injected proppant.

\section{References}

[1] R.Kh. Muslimov, R.G. Galeev, E.I. Suleimanov, Yu.A. Volkov, Problems of improving the scientific foundations of oil field development, Abstracts of 
the scientific and practical conference, Problems of the development of the oil industry of Tatarstan at the late stage of reserves development, Almetyevsk, 18-23 (1994)

[2] V.Sh. Mukhametshin, Estimation of the deposits' productivity index on the basis of indirect data at the stage of drawing up the first design documents, Oil and gas business 9, 3, 11 (2011)

[3] P. Davis Adelina, E. Michaelides, Efstathios Geothermal power production from abandoned oil wells, Energy 34, 7, 866-872 (July 2009)

[4] N.M. Wight, N.S. Bennett, Geothermal energy from abandoned oil and gas wells using water in combination with a closed wellbore, Applied Thermal Engineering 89, 908-915 (5 October 2015)

[5] Younes Noorollahi, Meysam Pourarshad, Saeid Jalilinasrabady, Hossein Yousefi, Numerical simulation of power production from abandoned oil wells in Ahwaz oil field in southern Iran, Geothermics 55, 16-23 (2015)

[6] Wen-Long Cheng, Tong-Tong Li, Yong-Le Nian, Kun Xie, Evaluation of working fluids for geothermal power generation from abandoned oil wells, Applied Energy 118, 238-245 (1 April 2014)

[7] Jianchun Guo, Songgen He, Yan Deng, Zhihong Zhao, New stress and initiation model of hydraulic fracturing based on nonlinear constitutive equation 27, 2, 666-675 (November 2015)

[8] K.F. Gabdrakhmanova, G.R. Izmailova, P.A. Larin, E.R. Vasilyeva, M.A. Madjidov, S.R. Marupov, Nomogram method as means for resource potential efficiency predicative aid of petrothermal energy, In Journal of Physics: Conference Series 1015, 3, 1 (2018)

[9] Jinzhou Zhaoa, Xuan Pua, Yongming Lia, Xianjie Heb, A semi-analytical mathematical model for predicting well performance of a multistage hydraulically fractured horizontal well in naturally fractured tight sandstone gas reservoir, Journal of Natural Gas Science and Engineering

[10] K.F. Gabdrakhmanova, G.R. Izmaylova, P.A. Larin, The way of using geothermal resources for generating electric energy in wells at a late stage of operation, In IOP Conference Series: Earth and Environmental Science 194, 8, 1-9 (November 2018)

[11] K. Gabdrakhmanova, G.R. Izmaylova, Equipment for paraffin removal from oil pipelines in order to ensureenergy saving in Arctic conditions, IOP Conf. Ser.: Earth Environ. - 2019, Sci.378 012038 (2019)

[12] K. Gabdrakhmanova, G.R. Izmaylova, Use of geothermal energy from abandoned oil wells, IOP Conf. Ser.: Earth Environ. - 2019, Sci.378 012053 (2019)

[13]Branko Damjanac, Peter Cundall, Application of distinct element methods to simulation of hydraulic fracturing in naturally fractured reservoirs 71, 283294 (January 2016)
[14] K.F. Gabdrakhmanova, G.R. Izmaylova, Method for selecting geothermal energy extraction technologies usingnomograms, J. Phys.: Conf. Ser. - 2019, 1333 072006 (2019)

[15] K.F. Gabdrakhmanova, G.R. Izmailova, L.Z. Samigullina, R.R. Ganiev, Information Technologies as a Means of the Professional Competence Formation in Technical University Students, Teaching Advances in Economics and Management 3, 59-64 (November 2019) ISSN: 2617-7102 